techniques to the diagnosis of Mendelian disorders. Both subjects are developing so fast that any review is likely to appear dated by the time it is in print. Blakemore and Mahoney's account of chorionic villus sampling is as topical as could be expected and their estimate of the miscarriage rate following this procedure is unlikely to require substantial amendment. John Phillips on molecular genetic techniques had an even more difficult task; my view is that he should have paid more attention to the principles of direct and indirect gene probing and taken his readers slowly and carefully through the problems of phase determination, informativeness, and the value of flanking markers. Many obstetricians (though I hope not too many genetic counsellors) find molecular genetics almost incomprehensible; they are unlikely to be illuminated by this very brief chapter.

With the exception of the chapters on medicolegal aspects (Shaw), ethical issues (Fletcher), and public policy (Omenn), where the issues are discussed in very readable form, Genetic Disorders and the Fetus is essentially a reference work. Its readers will be all those who need the facts on some aspect of prenatal diagnosis and need them fast. They are unlikely to be disappointed. Anything of significance published up to the end of 1985 is here. This book will be as influential on its subject as was the first edition.

David J H Brock

\section{Genetic and Population Studies in Wales}

Edited by P S Harper and E Sunderland. (Pp 433; $£ 27.00$.) Cardiff: University of Wales Press. 1986.

There is a certain timelessness about the study of Wales and of the Welsh, with the critical evidence that they provide on the ethnohistory of Britain, and the fact that it is now several years since the symposium was held on which this book is based does not detract from its interest. It aims to draw together the studies of Wales and her peoples made from a number of different viewpoints, currently scattered through a diversity of publications, and so provide both a general view of the Welsh and an appreciation of the heterogeneity and variety that exists within the country and the people. It succeeds remarkably well.

The first part gives the background. The late E G Bowen shows how the geography led to the political weakness of the principality throughout history; though each of the several lowland areas was the centre of considerable population, none was sufficiently outstanding or strong to become the national centre. Carter summarises historical population movements into Wales, the Anglo-Norman invasion $\overrightarrow{\vec{F}}$ after 1080 , the immigration to the industrial areas during the 18th and 19th centuries, and the diffuse immigration, associated with modern heightened $\frac{\overline{\bar{T}}}{\bar{\rho}}$ mobility, of the most recent period since the second $\overrightarrow{\widetilde{\sigma}}$

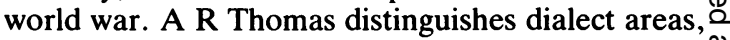
recognising a basic division between north and south, relevant to the interpretation of gene fre- $\vec{\theta}$ quency and epidemiological differences.

Part two concerns normal biological variation in $\vec{\omega}$ the Welsh, from which emerges again the extent of heterogeneity. In the anthropometric chapters Dennis demonstrates spatial patterns of biologicalin affinity similar to those shown by earlier investiga- on tors. Morgan Watkin provides the first of the gene frequency chapters, that on the ABO blood groups, $\stackrel{\vec{N}}{\mathrm{~N}}$ which distinguish the north from the south of theo country based on a sample of some 20000 . A second by D B Wile and his colleagues reports gene fre-T quencies derived from examination of infant speci- $\mathbb{D}$ mens of blood obtained for the national screening of phenylketonuria (more a demonstration of what could be done than a comprehensive analysis of $\vec{\theta}$ local variation). M T Smith summarises the results $\infty_{\infty}^{\infty}$ of a detailed genetic investigation in Anglesey and $G$ Fullerlove in Powys. An interesting population ino Wales is that of the gypsies, and E M Williams reports on their genetic markers but also drawso attention to the presence of recessively inheritedo disorders and the level of consanguinity that exists. The two chapters on dermatoglyphics both point to $\overrightarrow{\vec{O}}$ local heterogeneity. The final two chapters in this 3 section relate to demography and the use of parish? registers for genealogical studies.

It is the third part which will be of most interest to readers of this journal, for it concerns pathology Harper presents data on Mendelian disorders ando congenital malformations. Ashley presents stan dardised mortality ratios for different diseases, theô frequency of hospital admissions and consultations $₹$ in general practice by cause, and shows an excess? incidence of some diseases in the Welsh people:D cerebrovascular disease, coronary artery disease, $\underline{\underline{Z}}$ diabetes, prostatic hyperplasia, and carcinoma of the stomach and the oesophagus. The chapters on ${ }^{\circ}$ the newborn include an examination of the causes of 0 perinatal death using data from the Cardiff birth survey, and an interesting examination of the asso-0 ciations of serological polymorphisms with measureso of health and birth variables in a large random sample from Cardiff hospitals. K M Laurence $\stackrel{\text { S }}{+}$ presents material on neural tube defects in southo Wales, P J Gregory reports cytogenetic results on a. sample of some 7000 cases referred for investiga $-\mathbb{\Omega}$ ion, while Healy and Ellwood show that migrants from the Rhondda during 1950 to 1970 were ono 
average taller and heavier than men who continued to live in the valley.

Why this book was necessary is shown by the conrast between parts one and two on the one hand and part three on the other. None of the chapters on pathology appreciates the extent of the heterogeneity of population which is so well shown in their predecessors. This is, of course, understandable, for the investigations of genetic pathology belong to a later generation, and these should be regarded rather as a first analysis in the hope that other studies along the same lines will be instituted to explore the additional dimension of heterogeneity. There is a lot of material in this book, which is well illustrated and easy to read. As an introduction to the biological diversity within the Welsh population, and a source of reference for any who wish to pursue studies on the Welsh people, it is highly recommended.

\section{F ROBERTS}

The Dysmorphic Child: An Orthopedic Perspective By Michael J Goldberg. (Pp 448; \$80.00.) New York: Raven Press. 1987.

This book is written principally for the clinician who has an interest in the diagnosis and natural history of children affected by syndromes with "important musculo-skeletal deformity". That is, it deals with abnormalities of morphogenesis rather than with the skeletal dysplasias and myopathies. It will be of particular interest to medical geneticists and orthopaedic surgeons, and the former should not shy away from the subtitle, since the scope is much wider than just bone and joint deformity.

The syndromes are grouped together when there is similarity of physical appearance, the stated aim being to help with the diagnosis of dysmorphic children who initially appear to look similar. In addition to differential diagnosis, Dr Goldberg includes a review of the associated orthopaedic problems and each chapter ends with several pages of references, helpfully grouped according to the subjects within that chapter.

The subjects dealt with are: arthrogryposis and its syndromes, haemangioma syndromes, Marfan and Marfanoid habitus, selected 'short' and 'small' syndromes, syndromes of overgrowth, neurofibromatosis and the historical phakomatoses, EhlersDanlos syndromes, three chapters relating to congenital limb anomalies, growing up in a bad environment, and finally Down's syndrome and other chromosome abnormalities.

I found some of this excellent, in particular the chapters dealing with arthrogryposis, haemangioma syndromes, and the syndromes of overgrowth. These are good review articles of material it is not easy to find summarised elsewhere. Those on Marfan, neurofibromatosis, Ehlers-Danlos, and the chromosome abnormalities are accurate, as is the brief review of 'environmental' disorders. The chapters dealing with congenital limb anomalies attempt an impossible task, in view of the huge numbers of syndromes and the frequency of anomalies occurring in isolation. Only well known syndromes are included.

The number of references is rather overwhelming, and it would have been helpful to have some key ones noted. However, the book as a whole is well written and presented, and particularly valuable for its overview of the complex subjects mentioned above.

\section{RUTH WyNNE-DAVIES}

\section{Neuromuscular Diseases}

By Jaap Bethlem and Charlotte Knobbout. (Pp 158; £9.95.) Oxford: Oxford Medical Publications. 1987.

This small and concise book is written by an experienced neurologist and a physiotherapist. Its aim is to present information about neuromuscular diseases, briefly and succinctly, to doctors (consultants down to medical students), occupational and physiotherapists, and nurses. There are chapters on classification and examination and treatment, followed by ones on the individual muscular dystrophies, spinal muscular atrophies, and neuropathies. The chapter on genetics is deliberately brief, rightly recommending referral to a genetic centre, rather than encouraging readers of this book to proffer advice themselves. The tables giving categories of genetic muscular disorders are, however, useful.

One of the strengths of this book is its emphasis on natural history and management. This is because the authors are aware of what is happening to patients at home who no longer attend hospital and the physiotherapists' approach to management is valuable. Another merit of this book is clear photographs, which clearly illustrate signs of a disease, and which are particularly good in the section on testing muscle function. Each chapter has a series of postscripts which are helpful aids to memory or which are thought provoking. Some, however, are misleading because of their brevity. A disadvan- 